\title{
ASSESSING ECONOMIC IMPACT OF A REGIONAL UNIVERSITY
}

\author{
Kalyan Chakraborty, School of Business, Emporia State University \\ Dean Edmiston, School of Business, Emporia State University
}

dx.doi.org/10.18374/JIBE-14-1.1

\begin{abstract}
The financial contribution of a University on the local and state economy is often overlooked. These financial contributions are measured through impact analysis of university expenditures on regional economic sectors. We examined the economic impact of Emporia State University (Kansas) expenditures on the local and state economy. We used multipliers that are generated by the Bureau of Economic Analysis (BEA) in October 2012 based on U.S. National input-output model. The University's direct expenditures create indirect and induced effects on output, earnings, and employment for local and regional economic sectors. During the financial year 2012 the University and its ancillary units spent $\$ 336$ million directly into the state economy that generated $\$ 418$ million output, $\$ 131$ million income, and 4,430 jobs in Kansas. The University's overall output and earnings multipliers are 1.24 and 0.39 , respectively. In other words, for every dollar of expenditure by the university and its ancillary units creates $\$ 1.24$ of output and $\$ 0.39$ of household income. The University's employment multiplier is 2.88 implying every job University creates there are 2.88 additional jobs created in Kansas.
\end{abstract}

Keywords: Multipliers, University, Economic Impact, RIMS II 